\title{
Prevention of Broncho Pulmonary Dysplasia: Accuracy of Surfactant Dosage for Preterm Infants at Birth Based on Their Average Weights
}

\author{
Claire Crewe $^{1}$ and Naveen K Athiraman ${ }^{2 *}$ \\ ${ }^{1}$ Medical Student, Newcastle University, UK. \\ ${ }^{2}$ Consultant in Neonatal Paediatrics, Royal Victoria Infirmary, UK
}

*Corresponding author: Naveen K Athiraman, Royal Victoria Infirmary, Newcastle upon Tyne, NE1 4LP, UK

To Cite This Article: Claire Crewe, Naveen K Athiraman. Prevention of Broncho Pulmonary Dysplasia: Accuracy of Surfactant Dosage for Preterm Infants at Birth Based on Their Average Weights. 2020 - 8(6). AJBSR.MS.ID.001329. DOI: 10.34297/AJBSR.2020.08.001329.

Received: 畊April 29, 2020; Published: 些 May 15, 2020

\begin{abstract}
Introduction: Bronchopulmonary dysplasia (BPD) is defined as oxygen dependence at 36 weeks. Some pharmacological strategies used to decrease rates BPD include antenatal steroids, surfactant at birth and use of caffeine. In many neonatal units, surfactant is administered at birth in the delivery room in order to improve compliance of lungs and minimise lung injury as well as optimise ventilation. Knowledge on average weights at different gestational ages would be useful to deliver closer to accurate dose of surfactant, at birth.
\end{abstract}

Aim: To identify the average weights at all gestational ages from 22 weeks onwards and to calculate the average surfactant (curosurf) dose at every gestation.

Methodology: All newborn infants born and admitted to the regional neonatal unit were identified from Badgernet database, over a period of 10 years from January 2009 to November 2018. The data collection included gestational age (GA), birth weight and gender for all of the newborn infants admitted to the unit.

Results: A total of 7387 neonatal admissions were analysed during the 10-year period. The overall average weights at different gestational ages from 22 to 42 weeks were identified which was $505 \mathrm{gms}$ to $3728 \mathrm{gms}$, respectively.

Conclusion: On attending delivery room for extreme premature infants, $120 \mathrm{mg}$ curosurf seems appropriate until 25 weeks GA, $240 \mathrm{mg}$ for preterm infants until 30 weeks GA, 360mg and $480 \mathrm{mg}$ for borderline premature infants until 34 weeks and 36 weeks GA respectively.

Keywords: Preterm infants, Bronchopulmonary dysplasia, Chronic lung disease of newborn, surfactant, Average weights, Accurate dose

Abbreviations: Bronchopulmonary dysplasia- BPD; Gestational age- GA

\section{Introduction}

Bronchopulmonary dysplasia (BPD), otherwise known as chronic lung disease of the newborn affects mostly preterm infants due to their premature lungsand prolonged need of respiratory support [1]. This group of infants have surfactant deficiency at birthresulting in surfactant deficient lung disease, and the severity varies with degree of prematurity and other associated factors such as infection, meconium aspiration and pulmonary haemorrhage can further decrease or inhibit surfactant production temporarily [2]. As a routine, neonatal unit practices are to deliver surfactant at birth to all intubated premature infants to ensure maximum benefits in improving lung compliance and oxygenation as well as prevent BPD [3]. In our unit, all premature infants who require intubation at birth for respiratory distress receives surfactant soon after intubation in the delivery room. The literature suggests a surfactant dose (in case of curosurf) of $200 \mathrm{mg} / \mathrm{kg}$ at birth and follow-on dose of $100 \mathrm{mg} / \mathrm{kg}$, if still ventilated at around $12 \mathrm{hrs}$ of age [4]. Currently, initial surfactant dose is an estimate based on the gestational age. Neonatal team takes a surfactant vial, either $120 \mathrm{mg}$ or $240 \mathrm{mg}$, to the delivery room and the infant receives the full vial, which can result in either higher or lower the required dose. Curosurf is the commonly used exogenous surfactant in UK. 
The aim of this study is to identify the average weights at all gestational ages from 22 weeks onwards and the average curosurf dose at every gestation.

\section{Methods}

All newborn infants born and admitted to the regional neonatal unit were identified from Badgernet database, over a period of 10 years from January 2009 to November 2018. The data collection included gestational age (GA), birth weight and gender for all of the newborn infants admitted to the unit. The data was collected on an excel sheet and weights were calculated as an average for individual gestational ages. The same analysis was then used with male and female gender to identify the difference in average weights for gestational ages.

\section{Results}

A total of 7387 neonatal admissions were analysed during the 10 -year period, 3221 were females and 4159 males, 5 indeterminate and 2 unknown. The overall average weights at different gestational ages from 22 to 42 weeks are shown in Table 1 and average weights for female and male gender at various gestational ages are shown in Table 2 and 3 respectively.

Average surfactant dosage at 22 weeks gestational age is $238 \mathrm{mg} / \mathrm{kg}$, when $120 \mathrm{mg}$ vial is used. At 26 weeks GA $240 \mathrm{mg}$ vial is required to give a $285 \mathrm{mg} / \mathrm{kg}$ dose, 31 weeks GA required $360 \mathrm{mg}$ vial to give $231 \mathrm{mg} / \mathrm{kg}$, 35 weeks GA required $480 \mathrm{mg}$ to give $203 \mathrm{mg} /$ $\mathrm{kg}$ and 37 weeks GA required $600 \mathrm{mg}$ to give $210 \mathrm{mg} / \mathrm{kg}$ (Table 1 ).

\begin{tabular}{|c|c|c|c|c|c|c|}
\hline Gestation & Average weight & $\begin{array}{c}\text { Curosurf dose } \\
\text { (mg/kg) based on } \\
120 \mathrm{mg}\end{array}$ & $\begin{array}{l}\text { Curosurf dose } \\
\text { (mg/kg) based on } \\
240 \mathrm{mg}\end{array}$ & $\begin{array}{l}\text { Curosurf dose } \\
\text { (mg/kg) based on } \\
\text { 360mg }\end{array}$ & $\begin{array}{l}\text { Curosurf dose } \\
\text { (mg/kg) based } \\
\text { on } 480 \mathrm{mg}\end{array}$ & $600 \mathrm{mg}$ \\
\hline 22 & 505 & 237.62 & & & & \\
\hline 23 & 574.98 & 208.70 & & & & \\
\hline 24 & 658.63 & 182.19 & & & & \\
\hline 25 & 766.10 & 156.50 & & & & \\
\hline 26 & 842.09 & 142.50 & 285.00 & & & \\
\hline 27 & 980.77 & 122.35 & 244.70 & & & \\
\hline 28 & 1095.12 & & 219.15 & & & \\
\hline 29 & 1242.16 & & 193.21 & & & \\
\hline 30 & 1393.42 & & 172.24 & & & \\
\hline 31 & 1555.22 & & 154.32 & 231.48 & & \\
\hline 32 & 1746.08 & & 137.45 & 206.18 & & \\
\hline 33 & 1960.69 & & & 183.61 & & \\
\hline 34 & 2092.38 & & & 172.05 & 229.40 & \\
\hline 35 & 2363.84 & & & & 203.06 & \\
\hline 36 & 2630.53 & & & & 182.47 & \\
\hline 37 & 2853.38 & & & & 168.22 & 210.28 \\
\hline 38 & 3143.09 & & & & 152.72 & 190.90 \\
\hline 39 & 3356.86 & & & & 142.99 & 178.74 \\
\hline 40 & 3505.86 & & & & 136.91 & 171.14 \\
\hline 41 & 3659.34 & & & & 131.17 & 163.96 \\
\hline 42 & 3728.59 & & & & 128.74 & 160.91 \\
\hline
\end{tabular}

In females, average surfactant dosage at 22 weeks GA is $238 \mathrm{mg} /$ $\mathrm{kg}$, when $120 \mathrm{mg}$ vial is used. At 27 weeks GA $240 \mathrm{mg}$ vial is required to give a $243 \mathrm{mg} / \mathrm{kg}$ dose, 32 weeks GA required $360 \mathrm{mg}$ vial to give
$208 \mathrm{mg} / \mathrm{kg}$ and 35 weeks GA required $480 \mathrm{mg}$ to give $202 \mathrm{mg} / \mathrm{kg}$ (Table 2).

\begin{tabular}{|c|c|c|c|c|c|c|}
\hline Gestation & Average weight & $\begin{array}{c}\text { Curosurf dose } \\
\text { (mg/kg) based on } \\
120 \mathrm{mg}\end{array}$ & $\begin{array}{l}\text { Curosurf dose } \\
\text { (mg/kg)based on } \\
240 \mathrm{mg}\end{array}$ & $\begin{array}{c}\text { Curosurf dose } \\
\text { (mg/kg) based on } \\
360 \mathrm{mg}\end{array}$ & $\begin{array}{c}\text { Curosurf dose } \\
\text { (mg/kg) based on } \\
480 \mathrm{mg}\end{array}$ & $600 \mathrm{mg}$ \\
\hline 22 & 505 & 237.62 & & & & \\
\hline 23 & 563.03 & 213.13 & & & & \\
\hline 24 & 644.02 & 186.33 & & & & \\
\hline 25 & 777.62 & 154.32 & & & & \\
\hline
\end{tabular}




\begin{tabular}{|c|c|c|c|c|c|c|}
\hline 26 & 819.55 & 146.42 & 292.84 & & & \\
\hline 27 & 987.43 & 121.53 & 243.05 & & & \\
\hline 28 & 1053.8 & 113.87 & 227.75 & & & \\
\hline 29 & 1219.3 & & 196.84 & & & \\
\hline 30 & 1390.6 & & 172.59 & 258.88 & & \\
\hline 31 & 1556.2 & & 154.23 & 231.34 & & \\
\hline 32 & 1724 & & 139.21 & 208.82 & & \\
\hline 33 & 1987.8 & & 120.73 & 181.1 & & \\
\hline 34 & 2137.1 & & & 168.45 & 224.61 & \\
\hline 35 & 2368.5 & & & 152 & 202.66 & \\
\hline 36 & 2565.1 & & & 140.34 & 187.12 & \\
\hline 37 & 2854.8 & & & 126.1 & 168.14 & 210.28 \\
\hline 38 & 3194.9 & & & & 150.24 & 190.90 \\
\hline 39 & 3441.4 & & & & 139.48 & 178.74 \\
\hline 40 & 3539.4 & & & & 135.63 & 171.14 \\
\hline 41 & 3655.2 & & & & 131.32 & 163.96 \\
\hline 42 & 3488.6 & & & & 137.59 & 160.91 \\
\hline
\end{tabular}

In males, average surfactant dosage at 22 weeks GA is $238 \mathrm{mg} /$ $\mathrm{kg}$, when $120 \mathrm{mg}$ vial is used. At 26 weeks GA $260 \mathrm{mg}$ vial is required to give a $279 \mathrm{mg} / \mathrm{kg}$ dose, 32 weeks GA required $360 \mathrm{mg}$ vial to give
$204 \mathrm{mg} / \mathrm{kg}$ and at 35 weeks GA required $480 \mathrm{mg}$ to give $203 \mathrm{mg} / \mathrm{kg}$ (Table 3).

\begin{tabular}{|c|c|c|c|c|c|c|}
\hline Gestation & Average weight & $\begin{array}{c}\text { Curosurf dose } \\
\text { (mg/kg) based on } \\
120 \mathrm{mg}\end{array}$ & $\begin{array}{l}\text { Curosurf dose } \\
\text { (mg/kg)based on } \\
240 \mathrm{mg}\end{array}$ & $\begin{array}{c}\text { Curosurf dose } \\
\text { (mg/kg) based on } \\
360 \mathrm{mg}\end{array}$ & $\begin{array}{l}\text { Curosurf dose } \\
\text { (mg/kg) based } \\
\text { on } 480 \mathrm{mg}\end{array}$ & $600 \mathrm{mg}$ \\
\hline 22 & 505 & 237.62 & & & & \\
\hline 23 & 585.88 & 204.82 & & & & \\
\hline 24 & 665.95 & 180.19 & & & & \\
\hline 25 & 759.56 & 157.99 & & & & \\
\hline 26 & 859.83 & 139.56 & 279.12 & & & \\
\hline 27 & 977.04 & 122.82 & 243.64 & & & \\
\hline 28 & 1122.4 & 106.92 & 213.82 & & & \\
\hline 29 & 1254.6 & & 191.29 & & & \\
\hline 30 & 1396.2 & & 171.89 & 257.84 & & \\
\hline 31 & 1554.6 & & 154.38 & 231.57 & & \\
\hline 32 & 1761.1 & & 136.27 & 204.42 & & \\
\hline 33 & 1944.9 & & & 185.09 & & \\
\hline 34 & 2060.1 & & & 174.75 & 233 & \\
\hline 35 & 2357.6 & & & 152.7 & 203.6 & \\
\hline 36 & 3677.9 & & & 134.43 & 179.25 & \\
\hline 37 & 2847.8 & & & 126.41 & 168.55 & 210.28 \\
\hline 38 & 3095.5 & & & & 155.06 & 190.90 \\
\hline 39 & 3284 & & & & 146.16 & 178.74 \\
\hline 40 & 3478.6 & & & & 137.99 & 171.14 \\
\hline 41 & 3655.7 & & & & 131.3 & 163.96 \\
\hline 42 & 3752.3 & & & & 127.92 & 160.91 \\
\hline
\end{tabular}




\section{Discussion}

A $120 \mathrm{mg}$ surfactant vial gives around $237 \mathrm{mg} / \mathrm{kg}$ to $156 \mathrm{mg} /$ $\mathrm{kg}$ for 22 weeks to 25 weeks GA respectively. At 26 weeks, $240 \mathrm{mg}$ surfactant vial would provide $285 \mathrm{mg} / \mathrm{kg}$ and would be appropriate to use until 30 weeks GA. From 31 weeks GA infants will require $360 \mathrm{mg}$ vial to provide $231 \mathrm{mg} / \mathrm{kg}$ until 34 weeks providing $172 \mathrm{mg} /$ $\mathrm{kg}$. A 480mg vial will be appropriate for 35 and 36 weeks gestation giving $203 \mathrm{mg} / \mathrm{kg}$ and $180 \mathrm{mg} / \mathrm{kg}$. In infants born 37 weeks and above would benefit from $600 \mathrm{mg}$ vials to provide surfactant dose of $210 \mathrm{mg} / \mathrm{kg}$ until 42 weeks. This dosage is based on the aim to deliver $200 \mathrm{mg} / \mathrm{kg}$ or closer to this dose.

Many neonatal units aim to deliver surfactant at birth to provide adequate respiratory support from birth. Premature infants are surfactant deficient and giving surfactant improves compliance and minimises the respiratory support. However, the surfactant dose is an estimate as the infant is mostly not weighed in the delivery room or theatre.

Currently, there is minimal literature available on the weights of premature infants based on gestational age and gender. Here, we looked at admissions over a 10-year period to the tertiary neonatal unit in north east of England. This information will guide the neonatal teams to estimate the surfactant dose for different gestational ages and take the right vial to the delivery room or delivery theatre, specifically when attending a preterm delivery. This information will also help managing a sick term infant such as meconium aspiration syndrome where there may be a need for surfactant delivery at birth.

\section{Conclusion}

On attending delivery room for extreme premature infants, $120 \mathrm{mg}$ curosurf seems appropriate until 25 weeks GA, 240mg for preterm infants until 30 weeks GA, 360mg and 480mg for borderline premature infants until 34 weeks and 36 weeks GA respectively. Term infants requiring curosurf, a $600 \mathrm{mg}$ vial would be an appropriate dose. There is not a large difference in dosage between male and female gender.

\section{Acknowledgements}

Neonatal team for their support and hard work.

\section{Conflict of interest}

None

\section{References}

1. Kinsella JP, Greenough A, Abman SH (2006) Bronchopulmonary dysplasia. Lancet 29367(9520): 1421-1431.

2. Nkadi PO, Merritt TA, Pillers DM (2009) An overview of Pulmonary Surfactant in the neonate: Genetics, metabolism, and the role of surfactant in Health and disease. Mol Genet Metab 97(2): 95-101.

3. Schmidt B, Roberts R, Davis P, Doyle L, Barrington K, et al. (2006) Caffeine Therapy for Apnea of Prematurity. N Engl J Med 354: 2112-2121.

4. Cogo PE, Facco M, Simonato M, Verlato G, Rondina C, et al. (2009) Dosing of Porcine Surfactant Effect on Kinetics and Gas-Exchange in Respiratory Distress Syndrome. Pediatrics 124(5): e950-e957. 